\title{
Effect of socio-demographic characteristics on the prevalence of anemia among school going adolescent girls in Lucknow district, India
}

\author{
Beena Sachan ${ }^{1}$, MZ Idris ${ }^{2}$, Ashutosh Singh ${ }^{3}$
}

Assistant Professor, Department of Community Medicine, Era's Lucknow Medical College and Hospital, Lucknow, UP, India. ${ }^{2}$ Professor, Upgraded Department of Community Medicine, CSM Medical University, UP, Lucknow, India. ${ }^{3}$ Junior Resident (IIIrd year), Department of Pathology, LLRM Medical College, Meerut, India.

\begin{abstract}
Anemia is a serious public health concern in most developing countries and the prevalence of anemia is quite high among adolescent girls. A cross-sectional descriptive study was carried out among school going adolescent girls in urban as well as rural schools of the Lucknow district, Uttar Pradesh, India from October 2008 to September 2009 with the objectives of studying the prevalence of anemia and the various socio-demographic characteristics in relation to anemia. Multistage random sampling was used to select the requisite number of girls. A total of 847 school going adolescent girls between 1019 years of age were interviewed. Information regarding their socio-demographic characteristics was collected and the girls were also examined for presence or absence of pallor for anemia. Statistical analyses were done using percentage, Chi-square test, and odds ratio. The prevalence of anemia was found to be $55.6 \%$ and $57.9 \%$ in urban and rural school going adolescent girls respectively and significant association of anemia was observed with religion, caste and socioeconomic status $(p$ value $<0.05$ ). There is need to develop strategies for intensive adult education, nutrition education and dietary supplementation including anemia prophylaxis.
\end{abstract}

Keywords: Adolescent girls, Anemia, Socio-economic status, Lucknow district, India.

\section{Introduction}

Adolescence has been defined by the World Health Organization as the period of life spanning the ages between 10-19 years.' Protein energy malnutrition and iron deficiencies are major health concerns in adolescent girls. The common causes include inadequate intake of dietary iron, infectious diseases, deficiencies of micronutrients such as folate, vitamin B12, inherited conditions such as thalassemia and environmental pollutants such as lead. ${ }^{2}$ Adolescent girls need extra iron for menstruation in addition to growth and development. Iron deficiency anemia impairs cognitive and behavioral development resulting in reduced school performance. ${ }^{3}$ Further, low iron stores throughout childhood may contribute to a delayed menarche and impaired immune response. ${ }^{4}$ Anemia in adolescent girls in future attributes to high maternal mortality rate, high incidence of low birth weight babies and high perinatal mortality. ${ }^{5}$ In India, anemia is the second most common cause of maternal deaths, accounting for $20 \%$ of total maternal deaths. ${ }^{6}$ National Nutritional Anemia Prophylaxis Programme (NNAPP) was initiated in 1970 during fourth five-year plan with the aim to reduce the

\section{Practice points}

- Anemia is widely prevalent in India and the prevalence of anemia is quite high among adolescent girls.

- The prevalence of anemia in the Lucknow district was $56.3 \%$ among school going adolescent girls.

- A significant association of anemia was found with religion and caste.

- Prevalence of anemia was found maximum (64.0\%) in adolescent girls who belonged to SES-IV.

- The study provides an indication to implement intensive health education programs and to strengthen anemia prophylaxis programs for adolescent girls.

prevalence of anemia to $25 \%$. ${ }^{6}$ The present study focuses on the prevalence of anemia and its relationship with various socio-demographic factors among school going adolescent girls in the Lucknow district, India.

Correspondence: Dr. Beena Sachan, In front of Dr. Uma Singh, Railway station corner, Ashok Nagar, Ghatampur, Kanpur Nagar, UP, PIN-209206, India. E-mail: beenasachankgmu@gmail.com. 


\section{Material and methods}

The present cross-sectional study was carried out among school going adolescent girls in the Lucknow district, India from October 2008 to September 2009. An optimum sample size of 847 (593 urban and 254 rural) school going adolescent girls aged 10-19 years was obtained by an estimated prevalence of $50 \%$ anemia in adolescent girls with a precision of $5 \%$ at $95 \%$ confidence limit with a design effect of two. Multi-stage random sampling technique was used to select the requisite number of eligible girls.

Lucknow district is divided into urban and rural areas. The urban area is spread equally on both sides of Gomti River known as Cis Gomti and Trans Gomti. According to Nagar Nigam Lucknow, urban area is divided into six zones. From Cis Gomti two zones were randomly selected and similarly from Trans Gomti two zones were randomly selected. From each zone, one senior secondary school was selected randomly from the listed senior secondary schools. Similarly two blocks were selected randomly from eight blocks of the rural Lucknow. From each block, one senior secondary school was randomly selected from listed senior secondary schools. Finally, a total of six senior secondary schools, four schools from urban area and two schools from rural area were selected. Students from classes VI to XII of age group 10-19 years were selected. Students within the class were selected through systematic random sampling. In some schools of rural area, the numbers of students in the classes were not enough; therefore all the students of the class were invited to participate in the study as systematic random sampling was not possible. From the six schools, 593 adolescent girls from urban schools and 254 adolescent girls from rural schools were selected for the study.

Detailed information was collected on a predesigned and pretested proforma about the socio-demographic characteristics in relation to anemia by orally and supplemented with clinical examination. Social class was calculated using modified Kuppuswamy scale ${ }^{7}$ in urban area and Pareek scale ${ }^{7}$ in rural area. The statistical analysis was carried out using SPSS 16.0. for Windows.

\section{Results}

Among the 847 school going adolescent girls, 477 were found to be anemic with a prevalence of $56.3 \%$ (Table 1 ). About 55.6\% urban school girls and 57.9\% rural school girls were anemic and this difference was statistically insignificant. The prevalence of anemia among Hindu and Muslim girls was $57.8 \%$ and $47.5 \%$ respectively and this was statistically significant $(p<0.05)$ (Table 2$)$. The prevalence of anemia among urban adolescent girls was $57.1 \%$ (odds ratio 4.166) and 49\% in Hindu and Muslim girls respectively. Overall prevalence of anemia was highest among Scheduled Caste/Scheduled Tribe school going adolescent girls and was statistically significant $(\mathrm{p}<0.05)$.

Overall prevalence of anemia was highest (60.9\%) among girls of birth order of three to four. Among urban adolescent girls it was higher $(62.8 \%)$ in the girls with birth order of three to four while it was more prevalent (59.1\%) in girls with birth order of one to two in rural schools. Prevalence of anemia among urban and rural adolescent girls was found more $(56.3 \%)$ who lived in nuclear families. Among urban school going adolescent girls it was more (56.7\%) in girls who lived in nuclear families; however it was found to be more $(66.7 \%)$ (odds ratio 0.210$)$ in rural adolescent girls who lived in joint families.

Overall prevalence of anemia was found higher (64.0\%) in adolescent girls who belonged to socio-economic status (SES)-IV and it was statistically significant $(\mathrm{p}<0.05)$ (Table $3)$. Among urban adolescent girls, it was more prevalent $(69.3 \%)$ (Odds ratio 0.112) in girls with SES-IV; however in rural school going adolescent girls it was more prevalent in girls with SES-III.

\section{Discussion}

The Government of India has made the adolescent health as a part of Reproductive and Child Health ( $\mathrm{RCH})$ Package since 1997. The anemia in this age group has been identified as an important health problem by DeMaeyer \& AdielsTegman $^{8}$ followed by further reinforcement at the 1994 International Conference on Population and Development held at Cairo.

The study revealed that the overall prevalence of anemia as $56.3 \%$ in school going adolescent girls in the Lucknow district. Findings of the present study are almost in accordance with Kapoor et al. ${ }^{10}$ (60\%), Singh et al. ${ }^{11}$ (56\%), Rana et $a l .{ }^{12}(60 \%)$ and Seshadri et al. ${ }^{13}$ (63\%). However, Chaturvedi et al. ${ }^{14}$, Kotecha et al. ${ }^{15}$ and Agarwal ${ }^{16}$ reported a higher prevalence of $73.7 \%, 74.7 \%$ and $47.6 \%$ respectively. These differences in the prevalence of anemia may be due to difference in the study area and other associated factors.

Table 1: Prevalence of anemia among school going adolescent girls

\begin{tabular}{|c|c|c|c|c|}
\hline \multirow{2}{*}{ Anemi } & Urban & Rural & Total & $\boldsymbol{p}$-value \\
\cline { 2 - 5 } & Adolescent girls (\%) & Adolescent girls (\%) & Adolescent girls (\%) & $477(56.3 \%)$ \\
\hline Present & $330(55.6 \%)$ & $147(57.9 \%)$ & $370(43.7 \%)$ & 0.550 \\
\hline Absent & $263(44.4 \%)$ & $107(42.1 \%)$ & 847 \\
\hline Total & 593 & 254 & \\
\hline
\end{tabular}


Sachan et al. - Socio-demographic effect on anemia in adolescent girls

Table 2: Socio-demographic characteristics of anemia among school going adolescent girls

\begin{tabular}{|c|c|c|c|c|c|c|}
\hline \multirow[t]{2}{*}{ Religion } & \multicolumn{2}{|c|}{ Urban } & \multicolumn{2}{|c|}{ Rural } & \multicolumn{2}{|c|}{ Total } \\
\hline & Adolescent girls & $\begin{array}{c}\text { Anemia Cases } \\
(\%)\end{array}$ & Adolescent girls & $\begin{array}{c}\text { Anemia Cases } \\
(\%)\end{array}$ & Adolescent girls & $\begin{array}{c}\text { Anemia Cases } \\
(\%)\end{array}$ \\
\hline Hindu & 489 & $279(57.1 \%)$ & 238 & $141(59.2 \%)$ & 727 & $420(57.8 \%)$ \\
\hline Muslim & 104 & $51(49.0 \%)$ & 16 & $06(37.5 \%)$ & 120 & $57(47.5 \%)$ \\
\hline Total & 593 & $330(55.6 \%)$ & 254 & $147(57.9 \%)$ & 847 & $477(56.3 \%)$ \\
\hline$p$ value & \multicolumn{2}{|c|}{0.135} & \multicolumn{2}{|c|}{0.088} & \multicolumn{2}{|c|}{$0.036^{*}$} \\
\hline \multicolumn{7}{|l|}{ Caste } \\
\hline General & 222 & $124(55.9 \%)$ & 54 & $29(53.7 \%)$ & 276 & $153(55.4 \%)$ \\
\hline OBC & 231 & $120(51.9 \%)$ & 114 & $61(53.5 \%)$ & 345 & $181(52.5 \%)$ \\
\hline $\mathrm{SC} / \mathrm{ST}$ & 140 & $86(61.4 \%)$ & 86 & $57(66.3 \%)$ & 226 & $143(63.3 \%)$ \\
\hline Total & 593 & $330(55.6 \%)$ & 254 & $147(57.9 \%)$ & 847 & $477(56.3 \%)$ \\
\hline$p$ value & \multicolumn{2}{|c|}{0.204} & \multicolumn{2}{|c|}{0.152} & \multicolumn{2}{|c|}{$0.037^{*}$} \\
\hline \multicolumn{7}{|c|}{ Birth Order } \\
\hline $1-2$ & 359 & $189(52.6 \%)$ & 154 & $91(59.1 \%)$ & 513 & $280(54.6 \%)$ \\
\hline $3-4$ & 180 & $113(62.8 \%)$ & 73 & $41(56.2 \%)$ & 253 & $154(60.9 \%)$ \\
\hline$=5$ & 54 & $28(51.9 \%)$ & 27 & $15(55.6 \%)$ & 81 & $43(53.1 \%)$ \\
\hline Total & 593 & $330(55.6 \%)$ & 254 & $147(57.9 \%)$ & 847 & $477(56.3 \%)$ \\
\hline$p$ value & \multicolumn{2}{|c|}{0.069} & \multicolumn{2}{|c|}{0.887} & \multicolumn{2}{|c|}{0.212} \\
\hline \multicolumn{7}{|c|}{ Family type } \\
\hline Nuclear & 501 & $284(56.7 \%)$ & 200 & $111(55.5 \%)$ & 701 & $395(56.3 \%)$ \\
\hline Joint & 92 & $46(50.0 \%)$ & 54 & $36(66.7 \%)$ & 146 & $82(56.2 \%)$ \\
\hline Total & 593 & $330(55.6 \%)$ & 254 & $147(57.9 \%)$ & 847 & $477(56.3 \%)$ \\
\hline$p$ value & \multicolumn{2}{|c|}{0.235} & \multicolumn{2}{|c|}{0.140} & \multicolumn{2}{|c|}{0.968} \\
\hline
\end{tabular}

Key: OBC: Other Backward Class, SC/ST: Scheduled Caste/Scheduled Tribe, *Significant

Table 3: Prevalence of anemia in adolescent girls according to socio-economic status (SES)

\begin{tabular}{|c|c|c|c|c|c|c|}
\hline \multirow{2}{*}{ SES $^{\dagger}$} & \multicolumn{2}{|c|}{ Urban } & \multicolumn{2}{c|}{ Rural } & \multicolumn{2}{c|}{ Total } \\
\cline { 2 - 7 } & Adolescent girls & $\begin{array}{c}\text { Anemia Cases } \\
(\mathbf{\%})\end{array}$ & Adolescent girls & $\begin{array}{c}\text { Anemia Cases } \\
(\%)\end{array}$ & Adolescent girls & $\begin{array}{c}\text { Anemia Cases } \\
(\%)\end{array}$ \\
\hline I & 24 & $13(54.2 \%)$ & - & - & 24 & $13(54.2 \%)$ \\
\hline II & 229 & $100(43.7 \%)$ & 10 & $5(50 \%)$ & 239 & $105(43.9 \%)$ \\
\hline III & 190 & $113(59.5 \%)$ & 152 & $91(59.9 \%)$ & 342 & $204(59.6 \%)$ \\
\hline IV & 150 & $104(69.3 \%)$ & 92 & $51(55.4 \%)$ & 242 & $155(64.0 \%)$ \\
\hline Total & 593 & $330(55.6 \%)$ & 254 & $147(57.9 \%)$ & 847 & $477(56.3 \%)$ \\
\hline$p$ value & \multicolumn{2}{|c|}{$0.000^{*}$} & \multicolumn{2}{|c|}{0.695} & \multicolumn{2}{c|}{$0.000^{*}$} \\
\hline
\end{tabular}

${ }^{\dagger}$ None of the school going adolescent girls belonged to SES-V, * Significant 
In this study, a significant association of anemia was found with religion and caste $(\mathrm{p}<0.03)$. The overall prevalence of anemia was greater among Hindu girls $57.1 \%$ than Muslim girls $(49 \%)$ which could be due to the consumption of a vegetarian diet with low bioavailability of iron. It was similar to the findings of Kakkar et al. ${ }^{6}$ There is a high

prevalence of anemia among girls belonging to scheduled castes (Table 2) which is comparable to the study conducted by Singh $^{17}$ with urban population of Meerut City, Uttar Pradesh, India. The reason for this could be due to lack of money, either due to poverty or greater number of children in the family and lack of knowledge about child care practices.

In the present study, the association of anemia with birth order is found to be insignificant while Rawat et al. ${ }^{18}$ observed a significant association in their study. It is reported that in urban areas, anemia is comparatively less in birth order one or two than birth order 3-4 due to dilution of household resources and mother's attention, as the birth order in the family increases. In rural areas more girls are anemic when the birth order is one or two. This can be explained by the fact that older girls take care of their younger siblings, and in the process ignore their own health status.

A significant association between SES and the prevalence of anemia was also observed $(\mathrm{p}<0.000)$ which may be because of availability of high quality food with better SES and may be due to better awareness among parents about the nutritional requirement of girls during the adolescent period. Rawat et $a l^{4}{ }^{4}$ and Chaudhary et $a l .{ }^{19}$ also reported a significant association between SES and prevalence of anemia. In the present study, no significant association was observed with birth order and type of family.

\section{Conclusion}

Anemia is a serious public health concern in most developing countries and the prevalence of anemia is quite high among adolescent girls. We identified that more than half of the school going adolescent girls are suffering from anemia. Anemia has many critical health and nutritional implications in adolescent girls, which leads to poor pregnancy outcome, impaired school performance, decreased work productivity and other adverse outcomes. ${ }^{20}$ Safe and effective public health interventions are needed to address iron deficiency anemia in adolescent girls. A significant association of anemia with religion, caste and socio-economic status suggests a need to develop strategies for intensive adult education and to improve the socioeconomic status of the population through poverty alleviation programs. The study provides an indication to initiate strengthening of anemia prophylaxis programs for adolescent girls including nutritional education. Health education may be useful for improving the health status of adolescent girls and this could be imparted in all the schools with the help of heath personnel, NGOs. The teachers of the schools should be trained on health education and health promotion.

\section{Acknowledgement}

We are sincerely thankful to the principals of schools wherein the study was undertaken, for their valuable help extended during the study. We are thankful to Dr. Savita Jain and Dr. Reema Kumari for their valuable advice.

\section{References}

1. WHO. Programming for adolescent health and development. WHO Tech Rep Ser No. 886. Geneva: World Health Organization, 1996.

2. Mikki N, Abdul-Rahim HF, Stigum H, HolmboeOttesen G. Anaemia prevalence and associated sociodemographic and dietary factors among Palestinian adolescents in the West Bank. East Mediterr Health $J$ 2011;17:208-17.

3. WHO. Strategies for adolescent health and development: South-East Asia Region, Report of an inter-country consultation. New Delhi: World Health Organization, Regional office of South East Asia, 1998.

4. Rawat CMS, Garg SK, Singh JV, Bhatnagar M, Chopra H, Bajpai SK. Socio-demographic correlates of anemia among adolescent girls in rural area of district Meerut (UP). Indian J Community Med 2001;26:173-5.

5. Kulkarni MV, Durge PM, Kasturwar NB. Prevalence of anemia among adolescent girls in an urban slum. Natl $J$ Community Med 2012;3:108-11.

6. Kakkar R, Kakkar M, Kandpal SD, Jethani S. Study of anemia in adolescent school girls of Bhopal. Indian $J$ Community Health 2010;22:38-40.

7. Lal S, Adarsh, Pankaj. Textbook of community medicine (Preventive and Social Medicine). $1^{\text {st }}$ ed. New Delhi: CBS Publishers and Distributors, 2007.

8. DeMaeyer E, Adiels-Tegman M. The prevalence of anemia in the world. World Health Stat Q 1985;38:30216.

9. United Nations. Report of the International Conference on Population and Development. Cairo, 5-13 September 1994. New York: United Nations, 1995.

10. Kapoor G, Aneja S. Nutritional disorders in adolescent girls. Indian pediatr 1992;29:969-73.

11. Singh J, Singh JV, Srivastava AK, Suryakant. Health status of adolescent girls in slums of Lucknow. Indian J Community Med 2006;31:102-3.

12. Rana T. Age at menarche - Nutritional status and other associated factors in urban Hyderabad girls. PhD. Thesis. Submitted to National Institute of Nutrition, Hyderabad, 1983.

13. Seshadri S. A data base for iron deficiency anemia in 
India; Prevalence, etiology, consequences and strategies for control. Taskforce for Micronutrients Malnutrition Control, Department of Women and Child Development. New Delhi: Ministry of Human Resource Development, 1996.

14. Chaturvedi S, Kapil U, Gnanasekaran N, Sachdev HPS, Pandey RM and Bhanti T. Nutrient intake amongst girls belonging to poor socio-economic group of rural area of Rajasthan. Indian Pediatr 1996;33:197-202.

15. Kotecha PV, Patel RZ and Nirupam S. Prevalence of anemia among adolescent school girls, Vadodara district. Vadodara: Government Medical College, 2000.

16. Agarwal KN. Assessment of prevalence of anemia and iron stores in response to daily/weekly iron-folate supplementation in adolescent girls from urban slums of North East Delhi. New Delhi: UNICEF, 1998.

17. Singh R. Socio-demographic factors causing anaemia in adolescent girls in Meerut. Health Popul Perspec Issues 2008;31:198-203.

18. Rawat CM, Garg SK, Singh JV, Bhatnagar M, Chopra H, Bajpai SK. Prevalence of anaemia among adolescent girls in rural area of District Meerut, UP. Indian J Public Health 2001;45:24-6.

19. Chaudhary SM, Dhage VR. A Study of Anemia among adolescent females in the urban area of Nagpur. Indian JCommunity Med 2008;33:243-5.

20. Mittal MB, Abhay RS, Yadunath MJ, Vilasrao JK. An intervention on iron deficiency anemia and change in dietary behavior among adolescent girls. Int J Pharm Pharm sci 2011;3:40-2. 